\title{
As Áreas de Risco de Desastres nos Bairros Mucuripe e Manoel Dias Branco:
}

\author{
um desafio às políticas públicas de Defesa Civil
}

\section{Ricardo Rodrigues Catanho de Sena}

Mestre em Planejamento em Políticas Publicas - UECE

\section{Camila Holanda Marinho}

Doutora em Programa de Pós-Graduação em Sociologia pela Universidade Federal do Ceará UFC

Professora do Programa de Pós-Graduação em Políticas Públicas (PPGPP) da UECE

\section{Resumo}

A presente pesquisa trabalha as políticas públicas de defesa civil junto às áreas de risco de desastres nos bairros Mucuripe e Manoel Dias Branco e, cuja realidade pode ser replicada em outros bairros, cidades e Estados do Brasil, guardadas as devidas proporções e especificidades. Desta feita introdutoriamente trata-se dos desastres, correlacionando-os com a realidade cearense e na cidade de Fortaleza, em sequência didática abrange-se as atividades em si da Defesa Civil e suas fundamentações normativas, as quais norteiam as políticas públicas de Defesa Civil no Brasil e no Ceará. No que, em continuidade envereda-se pela pertinente realidade da Cidade de Fortaleza, afunilando-se pelos bairros de Mucuripe e Manoel Dias Branco com ênfase às suas áreas de risco de desastres, expondo-se suas principais mazelas com imagens e descrições técnicas. E, para finalizar arremata-se a pesquisa em comento por meio de reflexões e sugestões de soluções às problemáticas apresentadas, em subsídios e fomentos a outras discussões, tudo ora num prisma metodológico de cunho bibliográfico, com uma utilização de resultados, de ordem pura, num viés descritivo e qualitativo e cujo beneficiado mor é a própria sociedade, haja vista a viabilidade de fomento a políticas públicas as quais se direcionam a tutelar o maior de todos os bens sociais, qual seja, a vida.

Palavras-chave: Políticas Públicas. Defesa Civil. Áreas de Risco de Desastres. 


\begin{abstract}
The present research works the public policies of civil defense in the areas of disaster risk in the Mucuripe and Manoel Dias Branco neighborhoods, and whose reality can be replicated in other districts, cities and states of Brazil, keeping due proportions and specificities. This introductory article deals with disasters, correlating them with the reality of Ceará and in the city of Fortaleza. In a didactic sequence, it covers Civil Defense activities and its normative foundations, which guide the Civil Defense public policies in Brazil and in Ceará. In that, in continuity it is carried out by the pertinent reality of the City of Fortaleza, tapering itself by the neighborhoods Mucuripe and Manoel Dias White with emphasis to its areas of risk of disasters, exposing itself its main Social evils with images and technical descriptions. And, finally, the research in question is concluded by means of reflections and suggestions of solutions to the problems presented, in subsidies and fomentations to other discussions, all now in a methodological prism of bibliographic, with a use of results, pure order, In a descriptive and qualitative bias and whose beneficiary is society itself, due to the feasibility of fomenting public policies which are directed to protect the greatest of all social goods, namely, the life.
\end{abstract}

Key words: Public policy. Civil defense. Disaster Risk Areas. 


\section{Introdução}

Os desastres sempre fizeram parte da vida da Humanidade, em inúmeras ocasiões e em circunstâncias das mais variadas, muito embora tal terminologia esteja relacionada, na esfera do senso comum, como algo estritamente concatenado a grandes catástrofes e de ordem natural, como ciclones, terremotos, tsunamis, dentre outros. Desta feita, faz-se pertinente esclarecer primeiramente o entendimento técnico sobre "desastres", o qual, conforme Castro, por meio de sua obra Glossário de Defesa Civil (1998, p.52) externa a seguinte assertiva:

\footnotetext{
[...] resultado de eventos adversos, naturais ou provocados pelo homem, sobre um ecossistema (vulnerável), causando danos humanos, materiais e/ou ambientais e consequentes prejuízos econômicos e sociais. A intensidade de um desastre depende da interação entre a magnitude do evento adverso e o grau de vulnerabilidade do sistema receptor afetado. (Grifo nosso).
}

Neste sentido aduz-se que os mencionados eventos adversos também abrangem processos e fenômenos relativamente de menor monta, dentre os quais, cita-se: deslizamentos, inundações, subsidências e erosões, que por sua vez podem ocorrer naturalmente ou induzidos pelo homem, recebendo este último, a denominação técnica de desastres tecnológicos.

Em continuidade, cabe destacar que há uma correlação entre a magnitude do evento adverso e o nível de vulnerabilidade dos afetados pelo desastre, onde se viabiliza depreender que quanto menor for o nível de vulnerabilidade, potencialmente menores são os efeitos danosos dos eventos adversos junto àquela sociedade atingida.

$E$, por oportuno externa-se o entendimento de cunho técnico científico sobre vulnerabilidade social, suscintamente tratado como a propensão da população para os impactos negativos dos perigos e dos desastres (CUTTER, 2003; LASKA; MORROW, 2006), isto posto, aduz-se que estudar e compreender as respectivas vulnerabilidades de cada sociedade apresenta-se de fundamental importância para os planejamentos urbanos, no tocante a riscos potenciais de desastres, numa conduta essencialmente preventiva.

No âmbito do território cearense registram-se frequentes desastres quanto ao excesso ou escassez de águas, tais como nos anos de 2004, 2008 e 2009 com desastres ligados a inundações e enxurradas, ao passo que nos anos de 2012 a 2016 foram marcados por desastres de estiagens e secas, de tal forma que somente no ano de 2014, de acordo 
com informações do Sistema Integrado de Informações sobre Desastres (on line), a seca no Ceará prejudicou 176 municípios, de um total de 184 cidades as quais integram o Estado cearense, avolumando 2.440 .064 pessoas atingidas.

Em pertinência ao assunto em tela, cumpre externar que este ente pesquisador tem a seu favor, entre outros fatores, o conhecimento e a experiência de mais de vinte anos junto ao Corpo de Bombeiros Militar do Ceará, na condição atual de Oficial Superior e, com o exercício de diversificadas atribuições, dentre elas, a de Coordenador Estadual de Defesa Civil, além da autoria e publicação de Livros tais como "A Incorporação da Defesa Civil Estadual pelo Corpo de Bombeiros Militar do Ceará" (2012) e o livro "101 Perguntas e Respostas sobre o Corpo de Bombeiros Militar do Ceará - Comece a conhecê-lo e ame-o até depois do fim!" (2014).

Quanto às atividades de Defesa Civil, estas, no Brasil, no âmbito constitucional começaram a ter aspectos de políticas públicas em meados da década de 60 , mais precisamente por meio da Constituição Federal de 1967 (BRASIL, 1967), em seu capítulo II, o qual trata das competências da União, no seu art. 8º, XII: "organizar a defesa permanente contra as calamidades públicas, especialmente a seca e as inundações".

Ainda que sem o explícito termo "defesa civil", o texto normativo acima se correlaciona à pertinência funcional, principalmente considerando-se os termos "calamidades públicas", "seca e as inundações", além do caráter de perenidade nas atribuições de defesa, o que por sua vez arremete a reconhecimentos de demandas e problemas os quais requerem respectivos planejamentos e ações concernentes.

A Constituição Federal de 1988 (BRASIL, 1988), por sua vez aponta a Defesa Civil de modo mais voltado aos moldes de políticas públicas e de maneira mais aprimorada, uma vez que abrange aí a instituição de planejamentos com subsídio constitucional, pois ao tratar das competências da União, em seu art. 21, tem-se: "XVIII - planejar e promover a defesa permanente contra as calamidades públicas, especialmente as secas e as inundações". Tendo-se aí a inserção dos fatores planejamento e execução junto à responsabilidade da União e com força constitucional. Quanto ao artigo 22 (BRASIL, 1988), o qual trata das competências privativas da União para legislar, tem-se novamente tema defesa civil da seguinte forma: "XXVIII - defesa territorial, defesa aeroespacial, defesa marítima, defesa civil e mobilização nacional".

Destarte, a citada Carta Magna (BRASIL, 1988), no seu capítulo III, art. 144, o qual trata de modo inauguralmente especial da segurança pública, traz a figura da Defesa Civil concatenada a um dos órgãos explícitos de Segurança Pública, qual sejam os Corpos de Bombeiros Militares, da seguinte maneira:

Art. 144 A segurança pública, dever do Estado, direito e responsabilidade de todos, é exercida para a preservação da ordem pública e da incolumidade das pessoas e do patrimônio, através dos seguin- 


\section{As Áreas de Risco de Desastres nos Bairros Mucuripe e Manoel \\ Dias Branco: um desafio às políticas públicas de Defesa Civil}

tes órgãos: [...] § 5ํํs polícias militares cabem a polícia ostensiva e a preservação da ordem pública; aos corpos de bombeiros militares, além das atribuições definidas em lei, incumbe a execução de atividades de defesa civil. (Grifo nosso).

Neste sentido, Sena (2012, p.57,58), assevera que a coordenação da Defesa Civil no Estado do Ceará é exercida pelo Corpo de Bombeiros Militar do Ceará, a contar do ano de 2007, obedecendo a ditame constitucional estadual cearense (2008), conforme visto in litteris:

Art. 190. Incumbe ao Corpo de Bombeiros, no âmbito estadual, a coordenação da defesa civil e o cumprimento entre outras das atividades seguintes:

I - prevenção e combate a incêndio;

II - proteção, busca e salvamento;

III - socorro médico de emergência pré-hospitalar;

IV - proteção e salvamento aquáticos;

$\checkmark$ - pesquisas científicas em seu campo de atuação funcional;

$\mathrm{VI}$ - controle da observância dos requisitos técnicos contra incêndios de projetos de edificações, antes de sua liberação ao uso; e

VII - atividades educativas de prevenção de incêndio, pânico coletivo, proteção ao meio ambiente e atividades socioculturais. (Redação dada pela Emenda Constitucional n‥65, de dezesseis de setembro de 2009 - Diário Oficial de vinte e quatro de setembro de 2009. Redação anterior: VII - atividades educativas de prevenção de incêndio, pânico coletivo e de proteção ao meio ambiente. (Grifo nosso).

O texto acima denota atividades do CBMCE, as quais se correlacionam com a Defesa Civil no que tange aos desastres e que se somam ao conteúdo da Lei estadual oㅜ 13.875 (CEARÁ, 2007a) a qual, entre outras medidas, trata da reestrutura administrativa do Ceará, explicitando o posicionamento da Defesa Civil estadual no cerne do CBMCE, em conjunto com o seu respectivo Decreto no 28.656 (CEARÁ, 2007b) de 26 de fevereiro de 2007, o qual regulamenta a Lei supra dita e externa a atuação da Defesa Civil no território cearense, conforme se posta in litteris:

Art.1 Fica mantido o Sistema Estadual de Defesa Civil - SEDC, constituído por órgãos e entidades que integram a administração estadual, por enti- 
dades privadas e pela comunidade de modo geral, sob a coordenação da Coordenadoria Estadual de Defesa Civil, órgão pertencente à estrutura organizacional do Corpo de Bombeiros Militar do Estado do Ceará. Art.2ํㅗ̃o objetivos do Sistema Estadual de Defesa Civil - SEDC: I-articular, coordenar egerenciar as ações de defesa civil em nível estadual II - priorizar e apoiar as ações preventivas de preparação para emergências e desastres, resposta e reconstrução de cenários. Art. 3으 Para os efeitos deste Decreto considera-se: I - defesa civil: o conjunto de ações preventivas, de socorro, assistenciais e recuperativas, destinadas a evitar ou minimizar os desastres, preservar o moral da população e restabelecer a normalidade social; II - desastre: o resultado de eventos adversos, naturais ou provocados pelo homem, causando danos humanos, materiais ou ambientais e conseqüentes prejuízos econômicos e sociais; III - situação de emergência: o reconhecimento pelo poder público de situação anormal, provocada por desastres, causando danos superáveis pela comunidade afetada; IV - estado de calamidade pública: o reconhecimento pelo poder Público de situação anormal, provocada por desastres, causando sérios danos à comunidade afetada, inclusive à incolumidade ou à vida de seus integrantes. [...] (Sic) (Grifo nosso).

Isto posto, tem-se que as normas em alusão se correlacionam com a Lei Federal no 12.608, de 10 de abril de 2012 (BRASIL, 2012), que institui a Política Nacional de Proteção e Defesa Civil (PNPDEC) e, além do que, dispõe sobre o Sistema Nacional de Proteção e Defesa Civil (SINPDEC) e também trata do Conselho Nacional de Proteção e Defesa Civil (CONPDEC), bem como autoriza a criação de sistema de informações e monitoramento de desastres.

Faz-se perceptível de plano, a inclusão do termo "proteção" a esta nova política pública de defesa civil, de maneira a valorizar o aspecto intrínseco da segurança também por um viés proativo, em contrapartida a temerários procedimentos restritamente reativos, expressando assim um marco das políticas públicas de Defesa Civil.

\section{Métodos}

Ressalte-se que os aspectos metodológicos do presente trabalho, no que tange ao tipo, se faz de cunho bibliográfico, com uma utilização de resultados, de ordem pura e, já 
quanto à natureza, esta se apresenta qualitativa. Quanto aos fins, a pesquisa em epígrafe é tida como descritiva, embasando-se em variada literatura pertinente.

\section{Resultados e discussão}

No que tange a Fortaleza, capital do Estado do Ceará, esta urbe, a qual conta com $314.930 \mathrm{~km}^{2}$, (trezentos e quatorze mil novecentos e trinta $\mathrm{km}^{2}$ ) pautando-se pelo ano de 2015 e abriga uma população de aproximadamente 2.609 .716 milhões de habitantes contabilizados para o ano de 2016, bem como uma densidade demográfica (habitantes por $\mathrm{km}^{2}$ ) da ordem de 7.786,44 (sete mil setecentos e oitenta e seis) habitantes a cada km², apontando assim uma concentração urbana que deixa Fortaleza na condição de cidade com a maior densidade do Estado do Ceará, tudo consoante dados do Instituto Brasileiro de Geografia e Estatística (IBGE, 2016, on line), o que, por sua vez desagua em crônicas desigualdades socioeconômicas, dentre as quais, a existência de mais de 109.122 (cento e nove mil cento e vinte e dois) domicílios particulares ocupados em aglomerados subnormais, ou seja, de acordo com o IBGE (2010, p.3):

[...] o conjunto constituído por 51 ou mais unidades habitacionais caracterizadas por ausência de título de propriedade e pelo menos uma das características abaixo: - irregularidade das vias de circulação e do tamanho e forma dos lotes e/ou - carência de serviços públicos essenciais (como coleta de lixo, rede de esgoto, rede de água, energia elétrica e iluminação pública).

A revelação acima aponta para a realidade de bolsões de pobreza domiciliar ao longo de Fortaleza, numa simbiose às áreas de risco de desastres, ressaltando-se que estas últimas apresentam, entre outros aspectos, a escassez ou ausência dos serviços supra indicados, os quais, agregados a outras circunstâncias, tais como produção e despejos de lixos e detritos às margens de espelhos d'água e/ou em encostas, bem como construções irregulares, favorecem a possíveis ampliações de desastres, com destaque para o denominado período chuvoso. 
Em correlação ao dantes posto, o Instituto de Pesquisa e Estratégia Econômica do Ceará (IPECE, 2012) ${ }^{1}$ também externa, embasado em estudos da Organização das Nações Unidas (ONU) ${ }^{2}$ que a cidade de Fortaleza é a quinta mais desigual do mundo, o que por sua vez pode ser confirmado através de estudos elaborados pela entidade de pesquisa cearense anteriormente mencionada, onde mostra que dentre os dez (10) bairros mais ricos (com renda média entre $R \$ 2000$,01 e $R \$ 3659,54$ ) nove (09) estão concentrados em uma única Secretaria Executiva Regional da capital, ou seja, na Secretaria Executiva Regional II (SER II), tendo-se como única exceção, o bairro de Fátima o qual se encontra na Secretaria Executiva Regional IV. Quanto aos mais ricos, todos na SER II, estão os bairros Meireles, Guararapes, Cocó, De Lourdes, Aldeota, Dionísio Torres, Varjota, Praia de Iracema e, com destaque pela pertinência ao estudo em tela, o bairro do Mucuripe.

Em continuidade tem-se que estes desequilíbrios socioeconômicos se relacionam com vertentes multifatoriais, que vão desde a disseminação das chamadas áreas de risco de desastres até o planejamento urbano a curto, médio e longo prazo, os quais se concatenam diretamente com as políticas públicas de Defesa Civil, de tal maneira que somente no ano de 2013, a Defesa Civil Municipal de Fortaleza, registrou o quantitativo de 89 (oitenta e nove) áreas de risco, envolvendo 21.345 (vinte e um mil trezentos e quarenta e cinco) famílias, envolvendo registros de ocorrências tais como soterramento, alagamento, inundação, deslizamento de terras, entre outros.

Neste diapasão, a título de mais enriquecimento conjuntural, consoante dados fornecidos pela Defesa Civil de Fortaleza, expõe-se abaixo um esboço de um único dia de atuação por parte da Instituição mencionada, junto às Regionais, numa correlação entre as mesmas e suas respectivas quantidades de ocorrências, mais precisamente, no dia 02 de abril de 2016:

\section{Tabela 1 - Atendimentos pela defesa civil de Fortaleza}

\begin{tabular}{|l|l|}
\hline Regional & Qde. \\
\hline SER I & 3 \\
\hline SER II & 7 \\
\hline SER III & 7 \\
\hline SER IV & 7 \\
\hline SER V & 37 \\
\hline SER VI & 89 \\
\hline
\end{tabular}

Fonte: Defesa Civil de Fortaleza.

1 O Instituto de Pesquisa e Estratégia Econômica do Ceará (IPECE) é uma autarquia vinculada à Secretaria do Planejamento e Gestão do Estado do Ceará.

2 Organização Internacional, sediada em Nova lorque (EUA), formada por países que se reuniram voluntariamente para trabalhar pela paz e o desenvolvimento mundial. 


\begin{tabular}{|l|l|}
\hline CENTRO & 0 \\
\hline TOTAL & $\mathbf{1 5 0}$ \\
\hline
\end{tabular}

Também se externa que, consoante a Prefeitura Municipal de Fortaleza, a cidade desde 1997 tem a sua administração executiva dividida em Regionais e, atualmente está distribuída em seis Regionais mais a Regional do Centro, de modo a abranger um total de 119 (cento e dezenove) bairros, os quais podem ser visualizados pela ilustração a seguir:

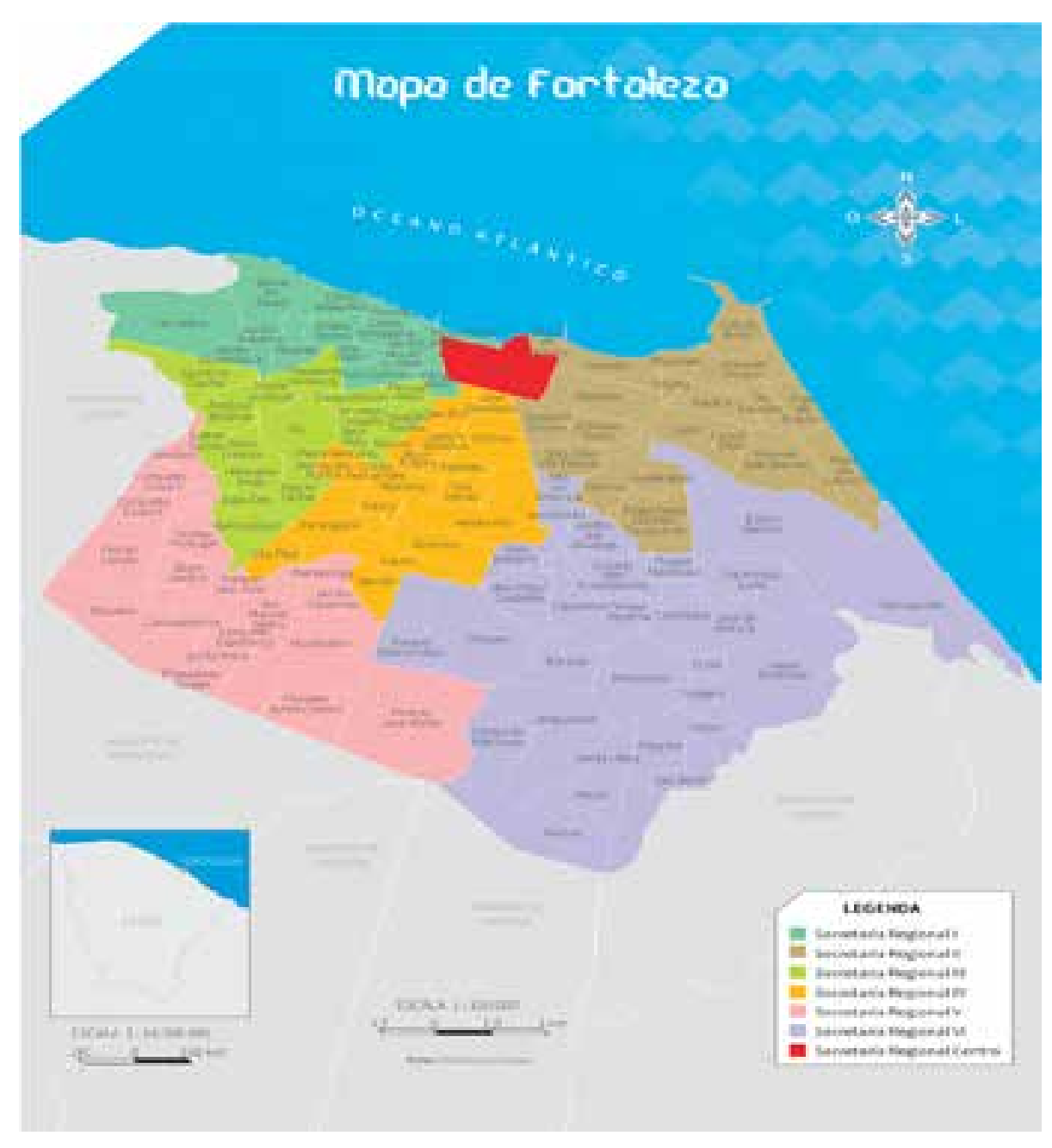

Fonte: Anuário do Ceará.

Neste sentido os bairros Mucuripe e Manoel Dias Branco, os quais, respectivamente apresentam as populações de treze mil setecentos e quarenta e sete (13.747) habitantes e mil quatrocentos e quarenta e sete (1447) habitantes, consoante dados do Anuário de Fortaleza (2010, on line), foram escolhidos considerando fatores tais como a limitação temporal para estudo das suas respectivas áreas de risco de desastres, as díspares realidades no tocante às 
suas estruturas edificadas, onde a primeira comporta itens de cunho industrial, com ênfase a produtos petrolíferos, com uma população de marcante desigualdade social, ao passo em que o segundo bairro, o qual é popularmente conhecido como "dunas", por sua vez comporta suntuosas mansões, bem como variados condomínios de luxo, por conseguinte com uma população majoritariamente de renda elevada, mas ambos com suas áreas de risco de desastres, no interior de zonas de pobreza, o que, por seu turno corrobora com a quebra do paradigma de que tais áreas existem exclusivamente em bairros de baixa renda.

Por este esteio, a Coordenadoria Municipal de Defesa Civil de Fortaleza aponta para a catalogação de 04 (quatro) grandes áreas de risco junto aos bairros Manoel Dias Branco e Mucuripe, desde o ano de 2012 até 2017, ressaltando-se que este último consta dos 09 (nove) bairros mais ricos da capital cearense e responde por 03 (três) das citadas grandes áreas, tal como pode ser visualizado a seguir:

Quadro 1 - Grandes Áreas de risco nos bairros Manoel Dias Branco e Mucuripe

\begin{tabular}{|c|c|c|c|}
\hline Áreas Vulneráveis & Tipo de Ameaça & Famílias & Observações \\
\hline $\begin{array}{c}\text { Mucuripe - Santa Tere- } \\
\text { zinha }\end{array}$ & Deslizamento & 779 & $\begin{array}{c}\text { Ocupação nas encos- } \\
\text { tas do morro. }\end{array}$ \\
\hline $\begin{array}{c}\text { Mucuripe - Riacho } \\
\text { Maceió/Comunidade } \\
\text { Saporé }\end{array}$ & Inundação & 98 & $\begin{array}{l}\text { Famílias habitam às } \\
\text { margens do riacho } \\
\text { Mirante Maceió. }\end{array}$ \\
\hline $\begin{array}{c}\text { Mucuripe ocupando } \\
\text { Manoel Dias Branco - } \\
\text { Morro de Gengibre }\end{array}$ & Deslizamento & 80 & $\begin{array}{l}\text { Famílias encostas do morro } \\
\text { as ento } \\
\text { em risco de soterra- } \\
\text { mento. }\end{array}$ \\
\hline $\begin{array}{l}\text { Mas encostas do } \\
\text { morro habitam famí- } \\
\text { lias situação de }\end{array}$ \\
\hline
\end{tabular}

Cabe destacar o fato de que os dados acima apresentam a característica de serem essencialmente mutáveis, em função de vários fatores, tais como a viabilidade de deslocamento de famílias, novos tipos de desastres, dentre outros e, em continuidade tem-se que a visualização de um pertinente conjunto de mapeamentos das áreas de risco de desastres a seguir, proporciona um melhor entendimento sobre a situação de diversos moradores os quais convivem com a iminência das tragédias diariamente: 


\section{As Áreas de Risco de Desastres nos Bairros Mucuripe e Manoel Dias Branco: um desafio às políticas públicas de Defesa Civil}

Figura 2 - Bairro Manoel Dias Branco (Morro do Gengibre)
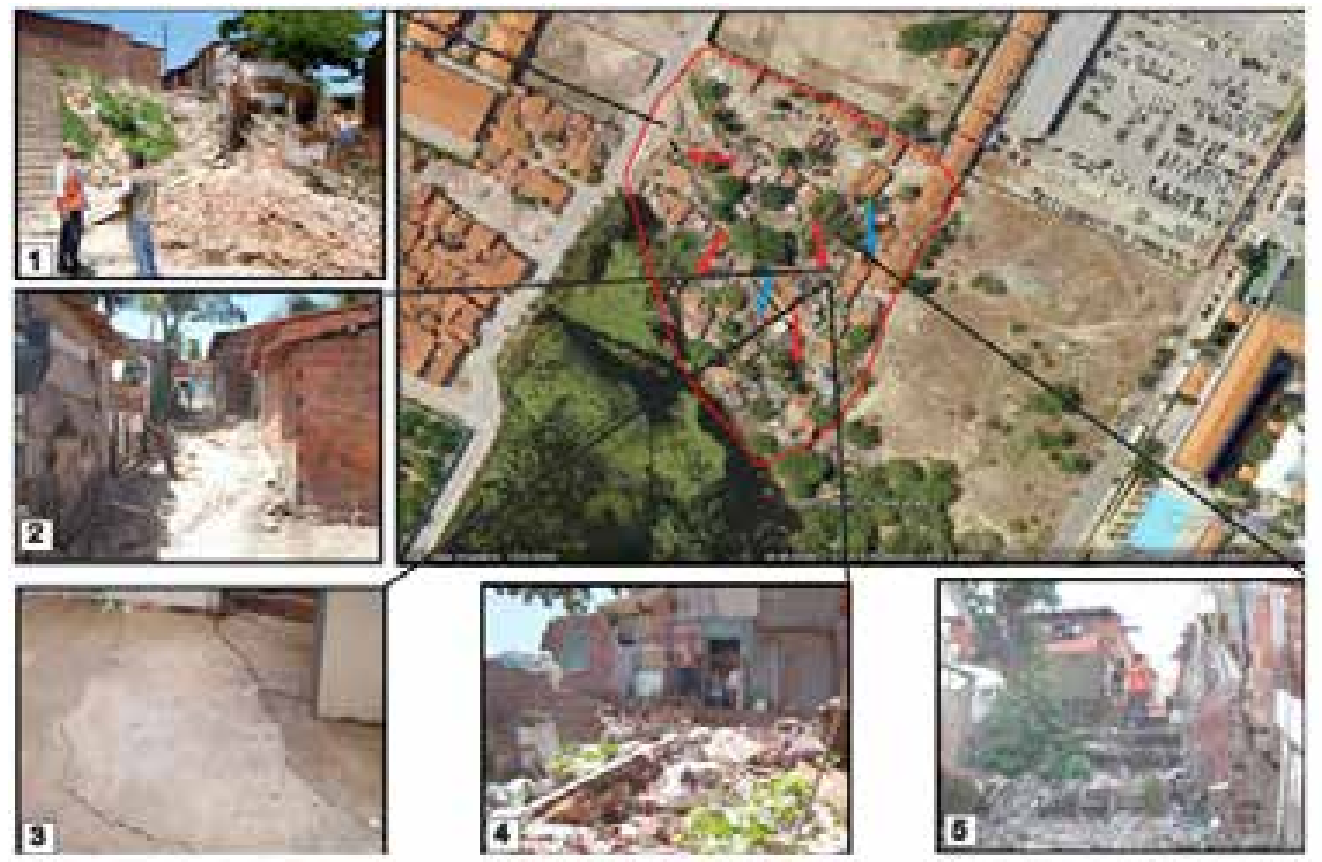

Fonte: CEDEC-CE.

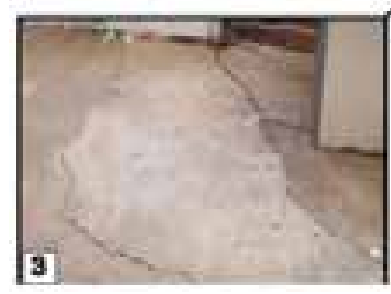

Legenda:

\begin{tabular}{|c|c|c|}
\hline $\begin{array}{r}\text { Delimitação do setor de } \\
\text { risco }\end{array}$ & Sentido da drenagem & $\begin{array}{c}\text { Sentido do movimento de } \\
\text { massa }\end{array}$ \\
\hline & & \\
\hline
\end{tabular}

Pelo acima exposto, verifica-se a realidade de ocupações irregulares nas encostas de dunas, o que, por sua vez arremete às condições de deslizamentos em cortes e aterros, com maior probabilidade por ocasião das chuvas, onde em resumo tem-se uma área de alto risco de desastre consoante a figura 1. No que tange às imagens 2 e 5, estas apresentam moradias de alta vulnerabilidade, com estruturas precárias e instáveis. Cumpre destacar a quantidade de entulho e lixo que, congregadas à força das águas, principalmente pluviais, numa região de terreno arenoso, ocasiona-se uma alta infiltração e saturação do solo, gerando assim uma instabilidade da encosta e grande risco de desastres, conforme as imagens 3 e 4, acima visualizadas.

A seguir vê-se o Morro de Santa Terezinha, o qual apresenta o seguinte mapeamento de área de risco de desastres: 
Figura 3 - Bairro Mucuripe (Morro Santa Terezinha)
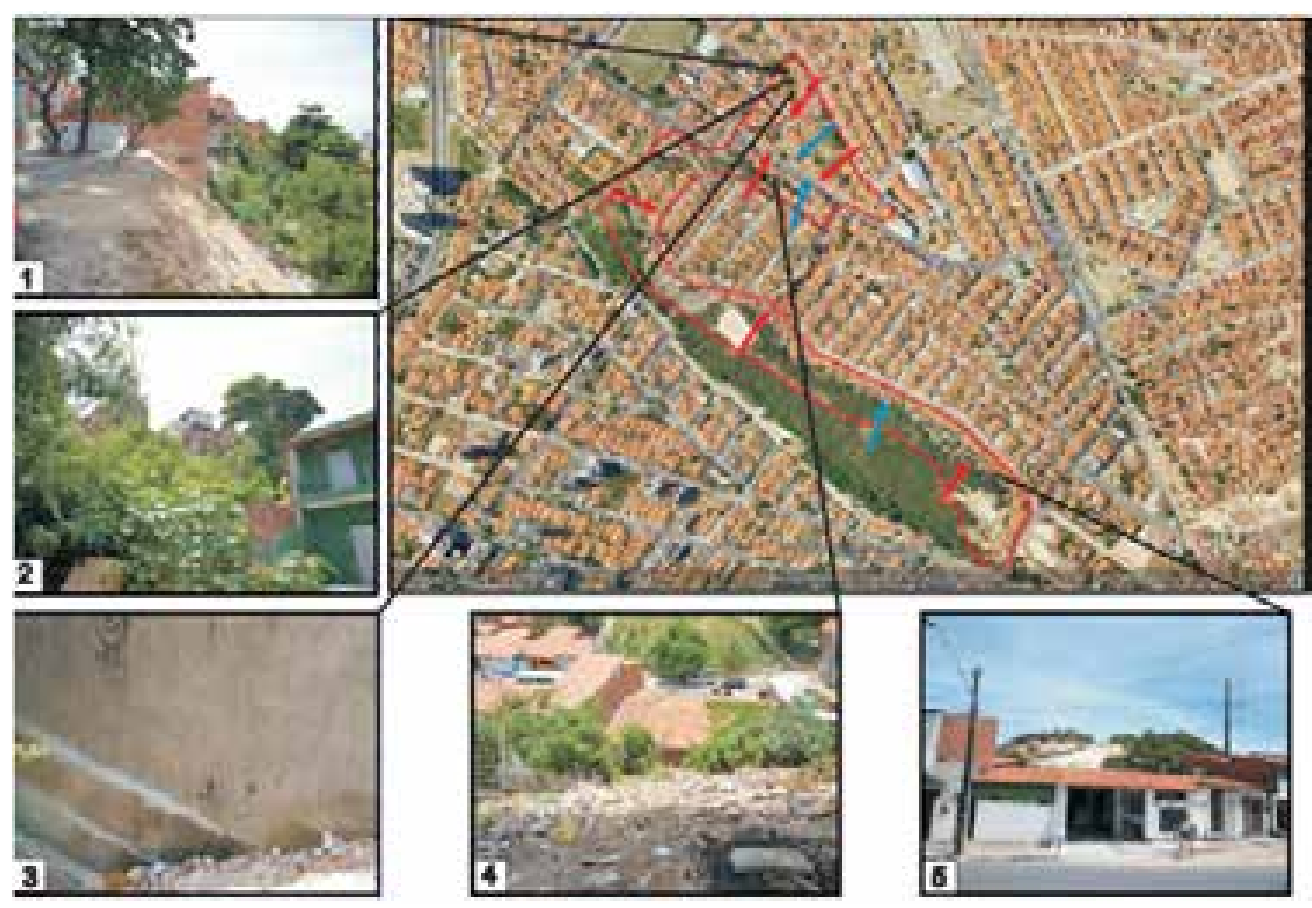

Fonte: Cedec-CE.

Legenda:

\begin{tabular}{|c|c|c|}
\hline $\begin{array}{c}\text { Delimitação do setor de } \\
\text { risco }\end{array}$ & Sentido da drenagem & $\begin{array}{c}\text { Sentido do movimento de } \\
\text { massa }\end{array}$ \\
\hline & & \\
\hline & & \\
\hline
\end{tabular}

O cenário acima expõe localidades com densa ocupação em áreas de dunas e com a presença de deslizamentos junto às encostas, o que por seu turno tem maior gravidade em função dos entulhos, lixos e detritos em geral ali encontrados, tudo somado a presença de uma rampa com aproximadamente 15 metros de altura e uma inclinação de cerca de 70․, abrangendo moradias de mais de um pavimento, (conforme imagens 1 e 2)

O fato de serem moradias com dois ou mais pavimentos, por si só já exige uma muito sólida estrutura e, nas condições observadas há um indubitável potencial de desestabilização por ação das águas e, por conseguinte, desmoronamentos das moradias em tela, as quais expõem sinais evidentes de desmoronamentos, dentre os quais, por meio das rachaduras em suas fundações, tudo atinente à imagem 3. Já a imagem 4 apresenta nova- 


\section{As Áreas de Risco de Desastres nos Bairros Mucuripe e Manoel Dias Branco: um desafio às políticas públicas de Defesa Civil}

mente a problemática do lixo e do entulho, os quais agregados ao fator águas, potencializam-se os riscos de desastres, literalmente, ladeira abaixo. No que diz respeito à imagem 5 verifica-se a aglomeração de edificações residenciais e comerciais, junto à base de uma encosta de duna, o que por sua vez gera risco iminente de desastres.

Quanto às imagens abaixo, estas se concatenam ao Morro do Mirante, situado no Bairro Mucuripe:

\section{Figura 4 - Bairro Mucuripe (Morro do Mirante)}
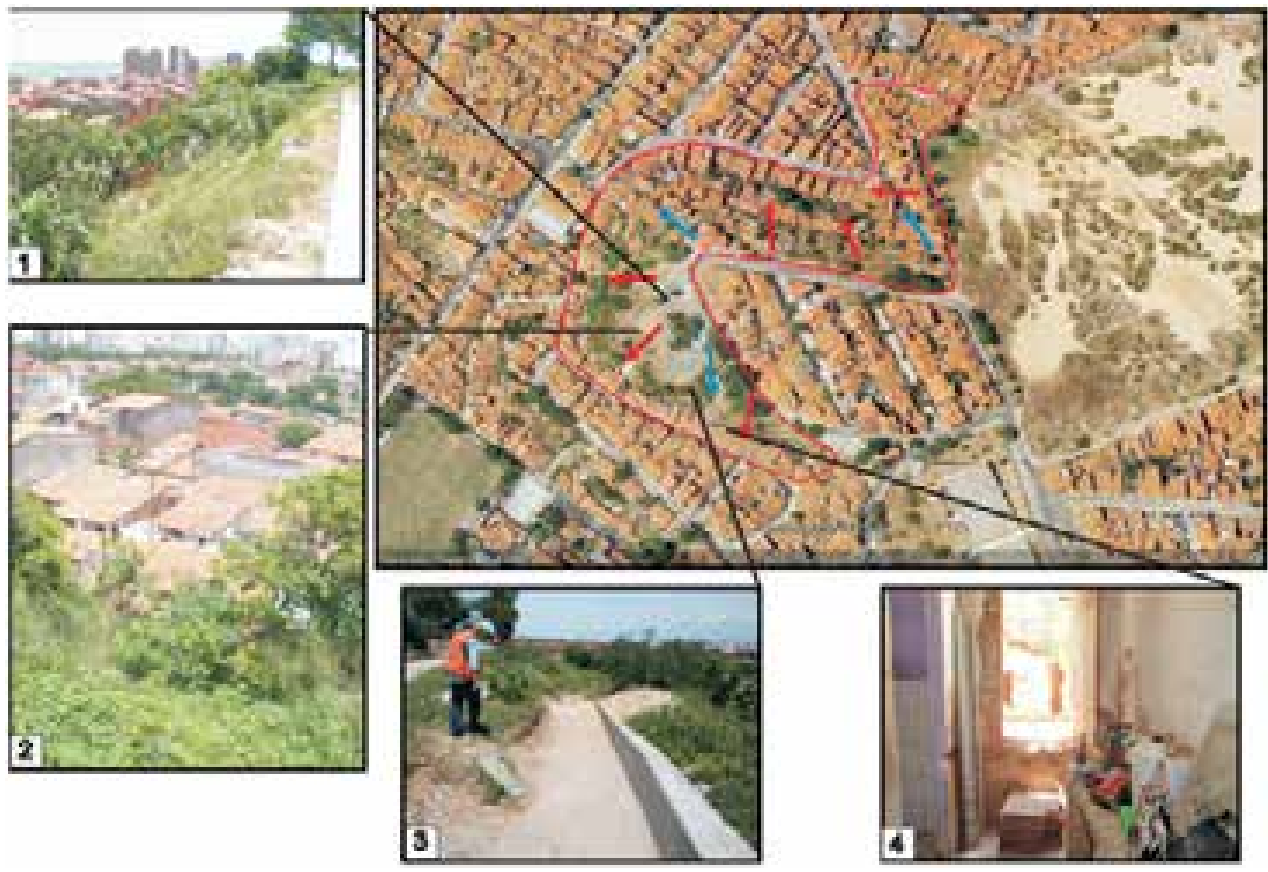

Legenda:

\begin{tabular}{|c|c|c|}
\hline $\begin{array}{c}\text { Delimitação do setor de } \\
\text { risco }\end{array}$ & Sentido da drenagem & $\begin{array}{c}\text { Sentido do movimento de } \\
\text { massa }\end{array}$ \\
\hline & & \\
\hline
\end{tabular}

Observando-se as imagens 1 e 2, vê-se uma densa ocupação junto a morros de dunas, abrangendo uma inclinação média de $45^{\circ}$ a $60^{\circ}$ e, desta feita com considerável potencial de desastre, considerando-se também e novamente a existência de lixo, entulho, detritos e águas, onde cabe concernente realce para a imagem 3, que por sua vez externa um trecho 
de sistema de drenagem, o qual se posta como parcial solução para as ameaças correlatas aqui, porém se faz imprescindível a sua não obstrução, dentre outros, pelos citados lixos, entulhos, detritos, principalmente por ocasião das ações das águas pluviais, tudo com o fito de minimizar e/ou se possível, extinguir a existência de perdas e danos, assim como os apresentados na imagem 4, a qual contém uma moradia imolada por deslizamento de terra e que por sua natureza não distingue quaisquer vítimas quanto a gênero ou idade.

Em conclusão aos mapeamentos das grandes áreas de risco de desastres nos bairros pesquisados, logo a seguir vê-se acostada ao Riacho Maceió, a comunidade Saporé, também no Bairro Mucuripe:

\section{Figura 5 - Bairro Mucuripe (Comunidade Saporé - Riacho Maceió)}
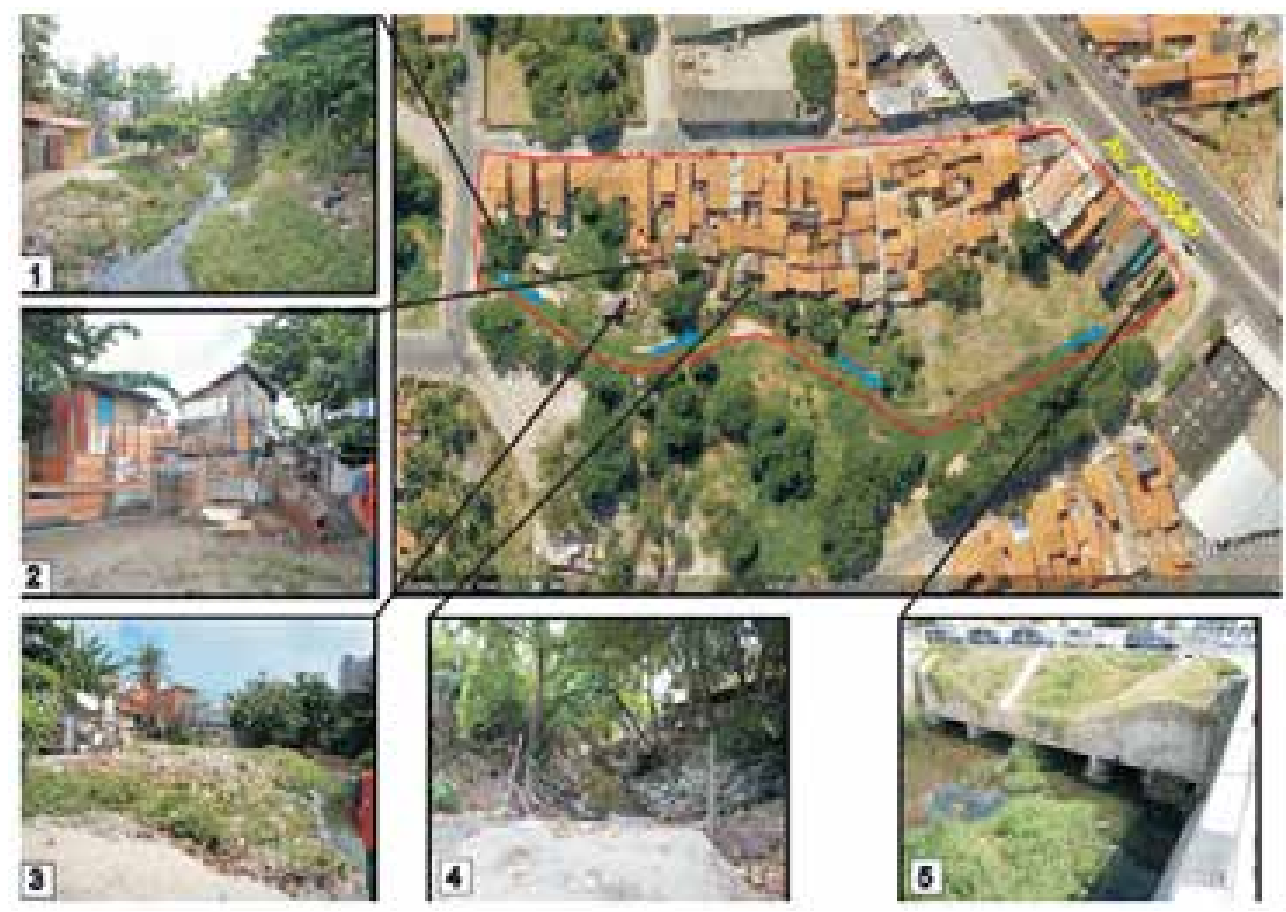

Fonte: Cedec-CE

Legenda:

\begin{tabular}{|c|c|}
\hline Delimitação do setor de risco & Sentido da drenagem \\
\hline & \\
\hline
\end{tabular}

No contexto em alusão visualiza-se frações do riacho Maceió, nas proximidades de sua foz, nas imediações da praia do Mucuripe, onde as imagens 1 e 2 apresentam casebres 
com alta vulnerabilidade, considerando-se, dentre outros aspectos, o potencial das enchentes e inundações, agravadas por ocasião das marés altas. Mais uma vez o fator lixo, entulhos e outros elementos contribuem de modo negativo, desta vez com ênfase ao assoreamento do riacho, como observado nas imagens 1, 3 e 4, enquanto que por outro lado, obras de drenagem, tais como vista junto à imagem 5 , com ampliação da galeria por onde o riacho mencionado escoa sob a Avenida Abolição, apresenta comprometimento de suas funções, não por acaso, com a obstrução à passagem das águas, por conta da existência de lixos, detritos, entulhos, dentre outros.

\section{Considerações Finais}

Depreende-se que os desastres sempre compuseram a História do homem e, provavelmente sempre farão parte da mesma, todavia estes mesmos infortúnios podem e devem ser trabalhados no sentido de minimizá-los ou até mesmo, sempre que possível, impedi-los, principalmente considerando o que é tutelado por estas ações, quais sejam os patrimônios materiais e o maior de todos: a vida, de modo a reduzir ao máximo os graus de vulnerabilidade das potenciais vítimas.

Neste contexto, a Capital do Estado do Ceará também se insere na condição de palco destes potenciais sinistros, de modo a se fazer necessária uma gama de atuações as quais perpassam por estudos, planejamentos e ações concernentes, envolvendo o binômio Estado/população e que, por sua vez ocorra na condição de política de Estado e não uma política de Governo, dada a necessidade de não haver solução de continuidade.

Neste sentido, ao tratar das áreas de risco de desastres, com maior delimitação e ênfase às localizadas nos bairros Mucuripe e Manoel Dias Branco, este texto as correlacionou com as políticas públicas de Defesa Civil, de maneira a fomentar as pertinentes discussões e também contribuir como subsídios para futuros estudos e debates, tudo em prol de potenciais soluções com primazia à prevenção e em plena atuação de governança e participação multissetorial, de tal modo que as pesquisas aqui postas, apontam para uma inviabilidade de solução perene para os problemas aqui apresentados, por parte unilateral do Estado, ou seja, faz-se imprescindível a colaboração da população, por exemplo, para as condutas de produção e manejo inadequado dos lixos, detritos e entulhos os quais potencializam os desastres nas suas áreas de risco, bem como a criação, manutenção e modificação de edificações em áreas totalmente inadequadas do ponto de vista estrutural e por conseguinte com comprometimento à segurança. 
Neste diapasão, no bojo dos desafios às pertinentes políticas de defesa civil devem constar um planejamento urbano o qual contenha ações como um trabalho de saneamento perene da lagoa do Gengibre; a relocação definitiva de determinados moradores, com a instalação de equipamentos os quais impeçam a reocupação dos espaços; a recomposição do ambiente de duna, somada à retirada do lixo e dos entulhos das encostas, somadas a obras de contenção; além da implantação e aprimoramento de diferentes sistemas de drenagem, porém também considerando em paralelo a tudo isto, um amplo e profundo trabalho de participação e conscientização das demais partes interessadas, dentre as quais, as comunidades direta e indiretamente afetadas pelas problemáticas em tela.

Neste esteio de conscientização, sugere-se medidas como o uso dos ambientes escolares locais como fonte de propagação das políticas públicas de Defesa Civil, tendo como público alvo não somente os alunos, mas além destes, os funcionários das escolas e os familiares dos dois grupos anteriormente citados, bem como campanhas publicitárias/ educativas em rádios, revistas, redes sociais, e outros meios mais de comunicação de massa.

Em suma, a complexidade dos problemas aqui postos exigem soluções paritariamente não simplórios e, os desafios às políticas públicas de defesa civil pertinentes perpassam por medidas adaptáveis consoante as demandas, como é da natureza das políticas públicas em geral e, neste caso em especial, com condições proativas e reativas, as quais têm em sua essência, uma retroalimentação de articulações, mas que de qualquer modo, se conduzem a uma segurança pública a qual se reverbera sob o lema de que "A DEFESA CIVIL SOMOS TODOS NÓS", numa corresponsabilidade de direitos e deveres difusos, porém com a devida ênfase ao direito à vida. 


\section{Referências Bibliográficas}

ANUÁRIO DE FORTALEZA. Mapa de Fortaleza. 2010. Disponível em: <http://www.anuariodefortaleza.com.br/fortalezenses/populacao-por-bairros-2010.php>. Acesso em: 12 maio 2017.

BRASIL. Constituição (1988). Constituição da república federativa do Brasil. Disponível em: <http://www.planalto.gov.br/ccivil_03/Constituicao/Constituicao.htm>. Acesso em: 12 maio 2017. Constituição (1967). Constituição da república federativa do Brasil. Disponível em: <http://www.planalto.gov.br/ccivil_03/constituicao/constituicao67.htm>. Acesso em: 12 maio 2017.

Lei Federal no 12.608, de 10 de abril de 2012. Ementa: Institui a Política Nacional de Proteção e Defesa Civil - PNPDEC; dispõe sobre o Sistema Nacional de Proteção e Defesa Civil - SINPDEC e o Conselho Nacional de Proteção e Defesa Civil - CONPDEC; autoriza a criação de sistema de informações e monitoramento de desastres; altera as Leis nos 12.340, de 10 de dezembro de 2010, 10.257, de 10 de julho de 2001, 6.766, de 19 de dezembro de 1979, 8.239, de 4 de outubro de 1991, e 9.394, de 20 de dezembro de 1996; e dá outras providências. Disponível em:<http://www.planalto.gov.br/ccivil_03/_Ato2011-2014/2012/ Lei/L12608.htm>. Acesso em: 13 abr. 2015.

CASTRO, Antônio Luiz Coimbra de. Glossário de defesa civil, estudo de riscos e medicina de desastres. 2 ed. Brasília: MPO, 2008.

CEARÁ. Constituição Estadual. Fortaleza: INESP, 2009.

CEARÁ. Lei Estadual no 13.875, de 07 de fevereiro de 2007a. Ementa: Dispõe sobre o Modelo de Gestão do Poder Executivo, altera a estrutura da Administração Estadual, promove a extinção e criação de cargos de direção e assessoramento superior, e dá outras providências. 
CEARÁ. Decreto Estadual no 28.656, de 26 de fevereiro de 2007b. Ementa: Reorganiza o Sistema Estadual de Defesa Civil - SEDC e o Conselho Estadual de Defesa Civil, dispõe sobre a Coordenadoria Estadual de Defesa Civil e dá outras providencias. Disponível em: $<$ http://www.defesacivil.ce.gov.br/index.php?option=com_content\&view=article\&id=74\&Itemid=155>. Acesso em: 14 maio 2017.

CUTTER, Susan. The vulnerability of science and the science of vulnerability. Annals of the Association of American Geographers, v.93, n.1, p.1-12, 2003.

INSTITUTO BRASILEIRO DE GEOGRAFIA E ESTATÍSTICA. Censo 2010: aglomerados subnormais - informações territoriais. Rio de Janeiro: IBGE, 2010. Disponível em: <http:// www.ibge.gov.br/home/presidencia/noticias/imprensa/ppts/000000151648112020134801 05748802.pdf >. Acesso em: 12 jan. 2017.

INSTITUTO BRASILEIRO DE GEOGRAFIA E ESTATÍSTICA. Mapas regionais, sociedade e economia - semiárido brasileiro. 2016. Disponível em: <http://geoftp.ibge.gov.br/cartas_e_ mapas/mapas_regionais/sociedade_e_economia/semi_arido/semiarido_brasileiro.pdf $>$. Acesso em: 03 jan. 2017.

INSTITUTO DE PESQUISA E ESTRATÉGIA ECONÔMICA DO CEARÁ. Perfil municipal de Fortaleza. Tema VII: distribuição espacial da renda pessoal. IPECE Informe, Fortaleza, n.42, p.1-11, out.2012. Disponível em: <http://www.ipece.ce.gov.br/informe/informe\%2042-ultimaversao.pdf>. Acesso em: 04 ago. 2017.

LASKA, Shirley; MORROW, Betty. Social vulnerabilities and hurricane Katrina: an unnatural disaster in New Orleans. Marine Technology Society Journal, New Orleans, v.40, n.4, p.1626, 2006.

SENA, Ricardo Rodrigues Catanho de. A incorporação da Defesa Civil Estadual pelo Corpo de Bombeiros Militar do Ceará. São Paulo: Nelpa, 2012.

SENA, Ricardo Rodrigues Catanho de. 101 Perguntas e Respostas sobre o Corpo de 
As Áreas de Risco de Desastres nos Bairros Mucuripe e Manoel Dias Branco: um desafio às políticas públicas de Defesa Civil

Bombeiros Militar do Ceará - comece a conhecê-lo e ame-o até depois do fim! São Paulo: Nelpa, 2014.

SENA, Ricardo Rodrigues Catanho de. A competência constitucional e infraconstitucional do Corpo de Bombeiros Militar do Ceará no âmbito da segurança pública. São Paulo: Nelpa, 2015. 